\title{
Proteomics in acute kidney injury-current status and future promise
}

\author{
Julie Ho • Allison Dart • Claudio Rigatto
}

Received: 15 October 2012 /Revised: 19 December 2012 / Accepted: 20 December 2012 /Published online: 18 April 2013

(C) IPNA 2013

\begin{abstract}
Pediatric acute kidney injury (AKI) is associated with increased morbidity, mortality and associated healthcare costs. Unfortunately, there are currently no effective therapies available, and this has been attributed in part to the late diagnosis of AKI. Therefore, significant efforts have been made to develop early diagnostic tools for AKI in the hope that early identification of renal injury will allow for effective therapeutic intervention. Different transcriptomic, proteomic and metabolomic technologies offer unbiased approaches to identifying novel biomarkers of AKI. This review will provide an overview of non-invasive pediatric AKI biomarkers. It will focus on unbiased technologies by using examples of biomarkers identified with "-omic" technologies and different methodological and implementation challenges will be highlighted. Finally, emerging proteomic techniques that may be applicable to biomarker discovery will be presented. Ultimately, the development of novel biomarkers of AKI may lead to the early diagnosis and effective therapeutic intervention of AKI to improve patient outcomes.
\end{abstract}

J. Ho $\cdot$ C. Rigatto

Section of Nephrology, Department Internal Medicine, University of Manitoba, Winnipeg, MB, Canada

J. Ho

Manitoba Centre for Proteomics and Systems Biology, University of Manitoba, Winnipeg, MB, Canada

A. Dart

Section of Nephrology, Department Paediatrics and Child Health, University of Manitoba, Winnipeg, MB, Canada

\section{J. Ho $(\bowtie)$}

Sections of Nephrology \& Biomedical Proteomics, Health

Sciences Centre, GE421C, 820 Sherbrook Street,

Winnipeg, MB R3A 1R9, Canada

e-mail: jho@exchange.hsc.mb.ca
Keywords Biomarker · Non-invasive diagnosis · Transcriptomics $\cdot$ Catabolomics $\cdot$ Metabolomics

\section{Overview}

Acute kidney injury (AKI) is associated with a significantly increased risk of mortality, as well as an increased risk for developing chronic kidney disease (CKD). Children are especially vulnerable and experience an increased incidence of AKI compared to adults following cardiac surgery $[1,2]$. Currently, the clinical diagnosis for AKI is made late, thus impeding effective therapeutic intervention. The early diagnosis of AKI is hampered by multiple factors, including the lack of a standardized definition for AKI, a flawed clinical gold standard for diagnosis (serum creatinine) and the complex underlying pathophysiology. While the former has now been largely rectified with new AKI diagnosis and staging guidelines [3], the latter issues continue to impede the early diagnosis of AKI. Therefore, the development of novel biomarkers for early AKI diagnosis is an identified research priority [3], and the purpose of this review is to discuss different strategies for biomarker discovery that may inform new diagnostics.

Mortality and morbidity associated with pediatric AKI

Acute kidney injury in the pediatric intensive care unit (PICU) is very common. Analysis of all children admitted to the PICU demonstrates a $10 \%$ incidence of AKI [4], which increases to $58-82 \%$ when considering severely ill PICU patients [5, 6]. It is associated with a two- to five-fold increase in short-term mortality $[5,6]$, and there is a dosedependent relationship such that increasing severity of AKI is associated with increased mortality [4]. Indeed, children with severe AKI requiring continuous renal replacement 
Fig. 1 Timing of clinical events in relation to pathological phases of acute kidney injury $(A K I)$. Adapted from Sutton et al. [21], used with permission

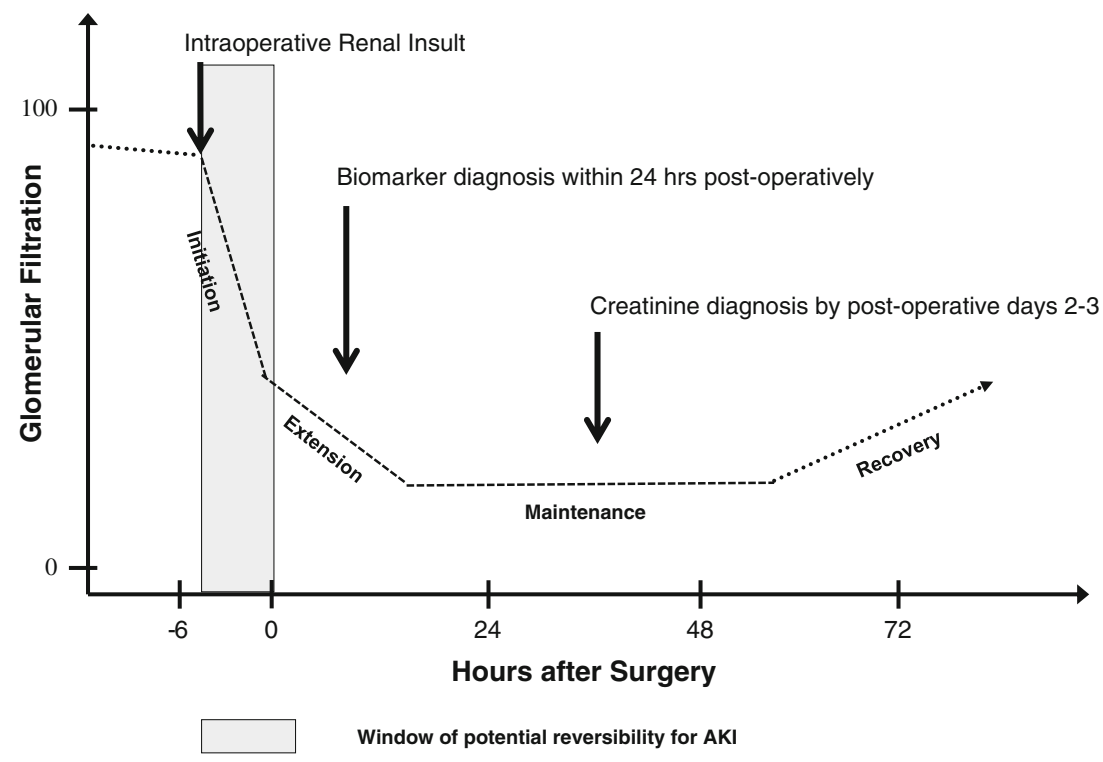

therapy have a survival rate of only $58 \%$ [7]. Importantly, $\mathrm{AKI}$ is an independent predictor of mortality in the PICU, demonstrating that it may be causally related to death [4]. Even mild increases in serum creatinine $(0.3 \mathrm{mg} / \mathrm{dL})$ are associated with increased mortality in children with decompensated heart failure [8]. Hospitalized children with AKI also have an increased risk for long-term mortality with a 3to 5-year survival rate of $80 \%$ [9].

Pediatric AKI is associated with considerable morbidity, including increased hospital and PICU length of stay [4], and the risk of developing CKD [10]. Approximately $10 \%$ of children with AKI in the PICU develop CKD in the 1-3 years

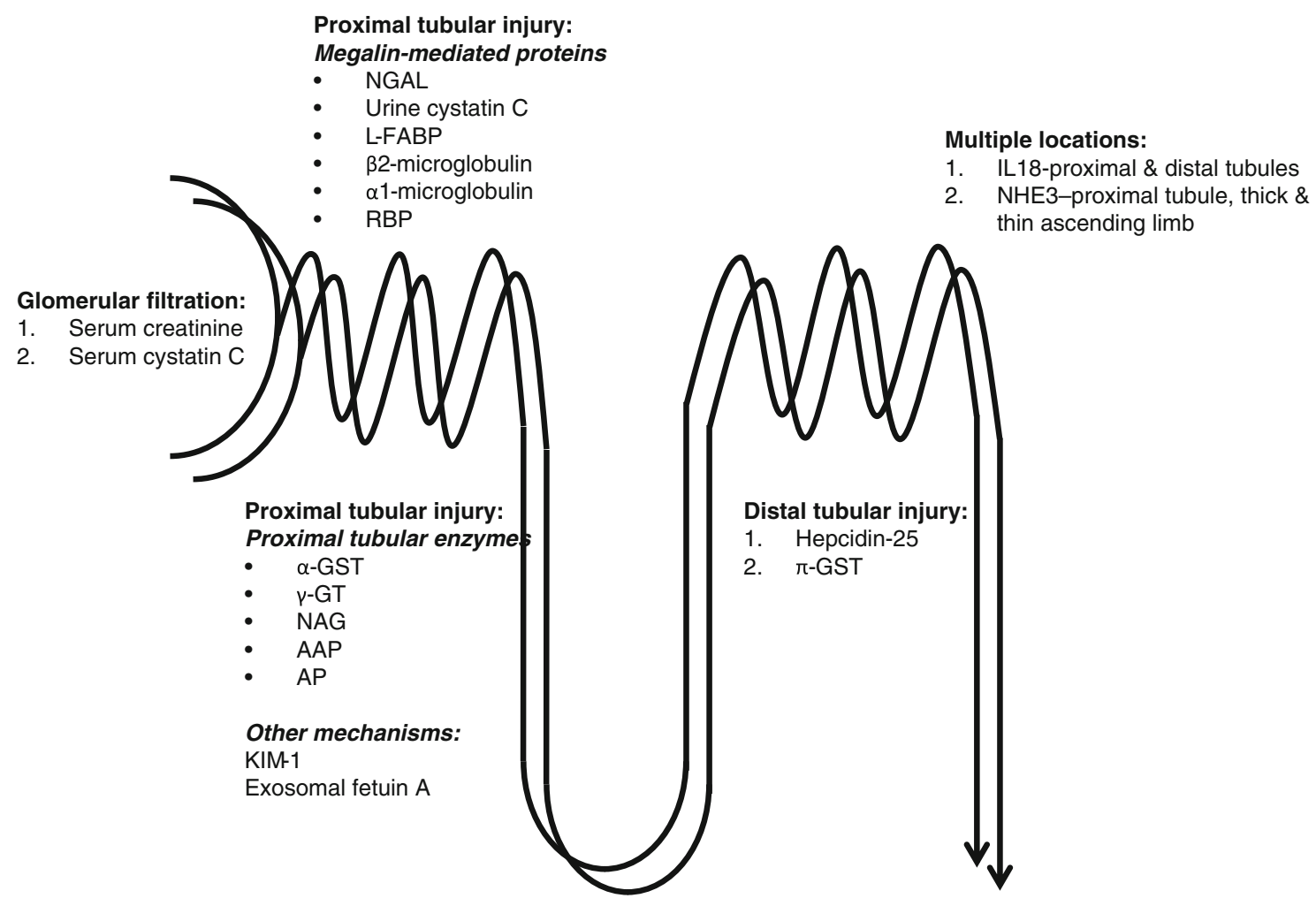

Fig. 2 Biomarkers of human acute kidney injury (AKI) reflect injury in different compartments. $N G A L$ neutrophil gelatinase-associated lipocalin, $K I M-1$ kidney injury molecule-1, $L$-FABP liver fatty acid-binding protein, $N A G \mathrm{~N}$-acetyl- $\beta$-(D)-glucosaminidase, IL18 interleukin $18, \alpha-G S T \alpha$ - glutathione-5-transferase, $\gamma$-GT $\gamma$-glutamyl transpeptidase, AAP Alanine aminopeptidase, $A P$ Alkaline phosphatase, $R B P$ Retinol binding protein, $N H E 3$ Sodium/hydrogen exchanger isoform, $\pi$-GST $\pi$-glutathione-Stransferase 
following discharge [11]. These findings also extend to hospitalized children with AKI who also demonstrate a higher risk of CKD [9]. While adult AKI is associated with an increased risk of CKD [12-14], the consequences of CKD in children are unique as there may be growth and developmental implications [15]. Taken together, these data suggest that pediatric AKI poses a significant healthcare burden, resulting in increased mortality and morbidity and a decreased quality of life [16]. Unfortunately, there are no specific interventions that have been proven to successfully treat AKI, and this lack has been attributed in part to its late diagnosis (Fig. 1).

\section{Challenges to early AKI diagnosis}

The complex, pathophysiological pathways involved in AKI have been an obstacle to developing early diagnostics and a contributing factor to the variable performance of novel biomarkers. AKI is a spectrum of events that can be conceptually separated into initiation, extension, maintenance and repair phases [17]. The initiation and extension phases are characterized by an insult, resulting in abnormal microvascular hemodynamics and white blood cell activation. Tubular injury can lead to necrosis and apoptosis of tubular cells [18], with sloughing into the lumen causing obstruction and backleak. Sublethally injured tubular cells lose their cytoskeletal integrity, brush border membranes and cell polarity. Mislocalization of adhesion molecules leads to loss of viable epithelial cells into the tubular lumen [19]. Surviving epithelial cells undergo dedifferentiation, proliferation and redifferentiation, leading to restitution of normal tubular epithelium during the repair phase of AKI [18].

Currently, the diagnosis of AKI is supported by serum creatinine measurements that are neither sensitive nor specific for renal injury [20]. Since creatinine indicates loss of glomerular filtration, it is only capable of detecting late AKI in the maintenance phase well after renal injury has evolved, and typically manifests after $\geq 50 \%$ loss of function (Fig. 1) [21]. Serum creatinine is also influenced by age, sex, muscle mass and diet, which are highly variable in children [22]. While serum cystatin $\mathrm{C}$ is a superior marker of glomerular filtration [23], it is still limited in detecting early tubular injury since it must be preceded by a loss of function. Early AKI in the initiation and extension phase is more likely to be detected by tubular proteins shed by viable or nonviable cells rather than loss of glomerular filtration. Finally, a comprehensive strategy of biomarker use that combines different components of renal injury may provide a more sensitive means for detecting early AKI (Fig. 2).

Novel biomarkers of AKI—-knowledge gaps

Promising AKI biomarkers include neutrophil gelatinaseassociated lipocalin (NGAL), interleukin-18 (IL18) and cystatin $\mathrm{C}$, and a summary of the relevant pediatric studies on novel biomarkers is given in Table 1 [1, 24-38]. However, many studies are limited by small numbers, single centers and selected high-risk populations. The Translational Research Investigating Biomarker Endpoints in Acute Kidney Injury (TRIBE-AKI) is a large multi-center prospective observational study with the aim of evaluating biomarkers of AKI in an adult $(n=1,219)$ and pediatric $(n=311)$ cardiac surgery population $[1,2,35,39]$. It is the largest study to date addressing the utility of NGAL, IL18 and cystatin C as biomarkers for AKI in children [1, 2, 35, 39]. While novel biomarkers have demonstrated excellent diagnostic performance in single-center studies, their discriminatory ability has proven less robust in multicenter studies (Table 1). Indeed, the pediatric TRIBE-AKI studies demonstrated that urine NGAL, urine IL18 and serum cystatin $\mathrm{C}$ had a receiver operating characteristic area under the time-concentration curve (AUC) of $0.71-0.81$, which only modestly improved upon the clinical risk prediction model $[1,35]$. This suggests that NGAL, IL18, cystatin C and clinical risk prediction alone are insufficient for the early detection of AKI. Therefore, new targets are needed in order to improve the overall diagnostic performance of biomarkers, and diagnostic accuracy may improve if biomarkers are interpreted as a panel, rather than in isolation $[24,38]$.

\section{Unbiased techniques for biomarker discovery}

Novel biomarker development can proceed from a traditional hypothesis-driven approach derived from the current understanding of AKI pathophysiology, or from an unbiased approach using "-omic" technologies. Each has their strengths and weaknesses, but this review will focus on unbiased techniques. Conceptually, the "-omic" technologies follow the lifespan of a protein. Genes (genomics) are transcribed (transcriptomics) into proteins (proteomics), which may then undergo post-translational modification prior to carrying out their designated function. Some proteins are enzymes which are only active in a specific conformational state (catabolomics), which then release metabolic products (metabolomics) (Fig. 3). Each step is tightly regulated, so changes in gene expression or transcript levels do not necessarily correlate with downstream effects. Therefore, protein expression may be more physiologically relevant. While metabolomics may discriminate between different disease states, metabolite identification does not necessarily identify the pathophysiological pathways involved. Regardless of the "-omic" technology used, it is important that novel biomarkers be translated into easy diagnostic assays that can rapidly process multiple samples (e.g. high throughput) to facilitate translation from bench to bedside. Biomarkers that require highly specialized techniques or equipment are unlikely to survive translation into an 
Table 1 Pediatric acute kidney injury biomarker studies and utility

\begin{tabular}{|c|c|c|c|c|c|c|}
\hline Biomarker & $\begin{array}{l}\text { Pediatric } \\
\text { population }\end{array}$ & $\begin{array}{l}\text { Number of } \\
\text { patients in } \\
\text { study }\end{array}$ & AKI definition & $\begin{array}{l}\text { Area under } \\
\text { the curve }\end{array}$ & $\begin{array}{l}\text { First author } \\
\text { of study/year }\end{array}$ & Ref. \\
\hline NGAL, urine & Cardiac surgery & 311 & $\mathrm{Cr} \times 2$ or dialysis & 0.71 & Parikh/2011 & [1] \\
\hline NGAL, plasma & Cardiac surgery & 311 & $\mathrm{Cr} \times 2$ or dialysis & 0.56 & Parikh/2011 ${ }^{\mathrm{a}, \mathrm{b}}$ & [1] \\
\hline NGAL, urine & Cardiac surgery & 220 & $\mathrm{Cr}>50 \%$ & 0.91 & Krawczeski/2011 ${ }^{\mathrm{a}}$ & {$[24]$} \\
\hline NGAL, plasma & Cardiac surgery & 338 & $\mathrm{Cr}>50 \%$ & 0.94 & Krawczeski/ 2011 & {$[25]$} \\
\hline NGAL, urine & Cardiac surgery & 338 & $\mathrm{Cr}>50 \%$ & 0.92 & Krawczeski/2011 & {$[25]$} \\
\hline NGAL, urine & Cardiac surgery & 71 & $\mathrm{Cr}>50 \%$ & 0.998 & Mishra/2005 & {$[26]$} \\
\hline NGAL, serum & Cardiac surgery & 71 & $\mathrm{Cr}>50 \%$ & 0.91 & Mishra/2005 & {$[26]$} \\
\hline NGAL, urine & Cardiac surgery & 196 & $\mathrm{Cr}>50 \%$ & 0.95 & Bennett/2008 & {$[27]$} \\
\hline NGAL, plasma & Cardiac surgery & 120 & $\mathrm{Cr}>50 \%$ & 0.96 & Dent/2007 & {$[28]$} \\
\hline NGAL, urine & ICU & 140 & RIFLE & 0.78 & Zapittelli/2007 & [29] \\
\hline NGAL, serum & $\mathrm{ICU}$ & 143 & $\begin{array}{l}\mathrm{BUN}>100 \text { or } \mathrm{Cr}>2 \\
\text { or dialysis }\end{array}$ & 0.68 & Wheeler/2008 & {$[30]$} \\
\hline NGAL, urine & ER & 252 & pRIFLE-R, I, F & $0.63-0.66$ & $\mathrm{Du} / 2011$ & {$[31]$} \\
\hline IL18, urine & Cardiac surgery & 311 & $\mathrm{Cr} \times 2$ or dialysis & 0.72 & Parikh/2011 ${ }^{\mathrm{a}, \mathrm{b}}$ & {$[1]$} \\
\hline IL18, urine & Cardiac surgery & 220 & $\mathrm{Cr}>50 \%$ & 0.84 & Krawczeski/ $2011^{\mathrm{a}}$ & {$[24]$} \\
\hline IL18, urine & $\begin{array}{l}\text { Cardiac surgery Nested } \\
\text { case control }(1.75: 1)\end{array}$ & 55 & $\mathrm{Cr}>50 \%$ & 0.75 & Parikh/2006 & {$[32]$} \\
\hline IL18, urine & ER & 252 & pRIFLE-R, I, F & $0.44-0.54$ & $\mathrm{Du} / 2011$ & {$[31]$} \\
\hline KIM-1, urine & $\begin{array}{l}\text { Adult \& pediatric } \\
\text { cross-sectional study }\end{array}$ & $74+20$ & $\mathrm{Cr}>50 \%$ & 0.83 & Han/2008 & {$[33]$} \\
\hline KIM-1, urine & ER & 252 & pRIFLE - R, I, F & 0.60 & $\mathrm{Du} / 2011$ & {$[31]$} \\
\hline L-FABP, urine & Cardiac surgery & 220 & $\mathrm{Cr}>50 \%$ & 0.77 & Krawczeski/2011 ${ }^{\mathrm{a}}$ & [24] \\
\hline L-FABP, urine & Cardiac surgery & 40 & $\mathrm{Cr}>50 \%$ & 0.81 & Portilla/2008 & {$[34]$} \\
\hline Cystatin C, serum & Cardiac surgery & 288 & $\mathrm{Cr}>50 \%$ & 0.81 & Zappitelli/2011 $1^{\mathrm{a}, \mathrm{b}}$ & {$[35]$} \\
\hline Cystatin C, serum & Cardiac surgery & 374 & $\mathrm{Cr}>50 \%$ & 0.81 & Krawczeski/2010 & {$[36]$} \\
\hline Cystatin C, serum & Cardiac surgery & 100 & $\mathrm{Cr}>50 \%$ & 0.67 & Hassinger/2012 & {$[37]$} \\
\hline Albumin, urine & Cardiac surgery & 294 & AKI stage $\geq 1$ & $0.72-0.82$ & Zappitelli/2012 ${ }^{\mathrm{a}, \mathrm{b}}$ & {$[38]$} \\
\hline$\beta 2$-microglobulin, urine & ER & 252 & pRIFLE- R, I, F & 0.59 & $\mathrm{Du} / 2011$ & {$[31]$} \\
\hline
\end{tabular}

AKI Acute kidney injury, NGAL Neutrophil gelatinase-associated lipocalin, IL18 interleukin-18, L-FABP liver-type fatty acid-binding protein, KIM1 kidney injury molecule 1, ICU intensive care unit, $E R$ emergency room, $C r$ creatinine, $p R I F L E$ pediatric Risk, Injury, Failure, Loss, End-stage renal disease,

${ }^{a}$ Biomarker was analyzed in addition to a base clinical model

${ }^{\mathrm{b}}$ A multi-centre study

effective clinical test. Selected examples of human AKI models will be used to demonstrate how unbiased technologies can be useful for biomarker discovery.

\section{Transcriptomics}

A transcriptome-wide interrogation strategy using microarray technology discovered NGAL, a novel protein, to be upregulated in a mouse model of ischemia reperfusion injury (IRI) [40]. NGAL protein expression was subsequently detected in injured proximal tubular cells [40]. NGAL is an antimicrobial peptide that forms a complex with ironbinding siderophores. The NGAL:siderophore:Fe complex has been found to be protective in renal IRI by up-regulating heme-oxygenase 1 , preserving proximal tubular $\mathrm{N}$-cadherin and inhibiting cell death [41]. Interestingly, this action was found to be dependent on NGAL being bound to the siderophore:Fe complex and was blocked by the iron chelator, deferoxamine, suggesting that $\mathrm{Fe}$ binding is a key mediator of NGAL's effect [41]. Exogenously administered NGAL has also been shown to ameliorate ischemic AKI in a mouse model of IRI [42]. Due to the early timing of NGAL release and its dose relation to severity of renal insufficiency, NGAL was postulated to be an early AKI biomarker, and this has since been confirmed in multiple human AKI biomarker studies [43].

Kidney injury molecule-1 (KIM-1) was discovered to be up-regulated in a rat model of IRI utilizing a subtractive 
Fig. 3 Overview of different types of strategies for biomarker discovery. SELDI TOF-MS

Surface enhanced laser desorption ionization time-offlight mass spectrometry, CE MS-MS Capillary electrophoresis mass spectrometry, 2D DIGE Two-dimensional fluorescence difference gel electrophoresis, $N M R$ Nuclear magnetic resonance, $M S$ - $M S$ Tandem mass spectrometry, IL18 Interleukin 18, NHE3 Sodium/hydrogen exchanger isoform, $M C P-1$ Monocyte chemoattractant protein-1

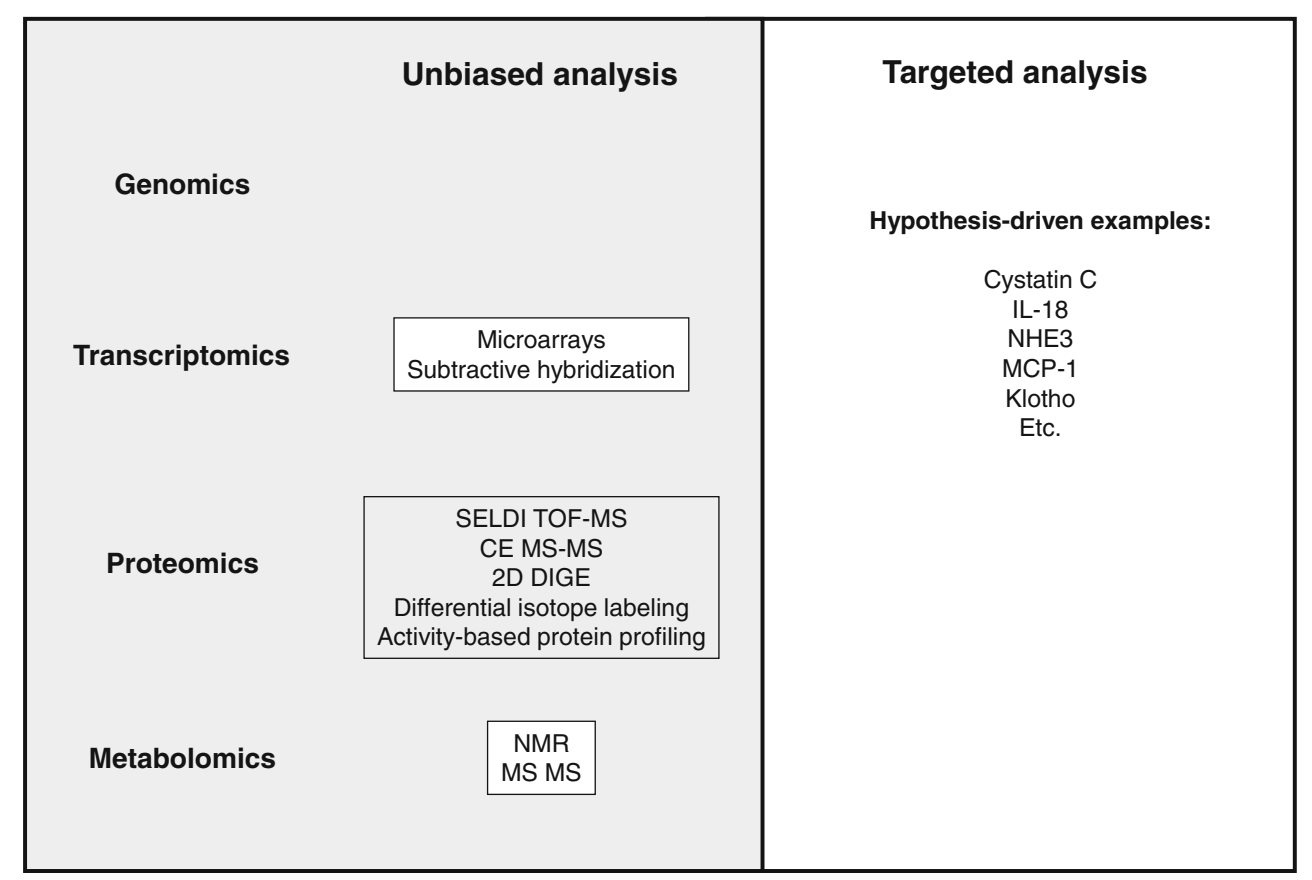

hybridization approach [44] and was shown to be a marker of proximal tubular injury [45]. KIM-1 is a phosphatidylserine receptor which recognizes apoptotic cells and enhances their clearance by directing them to lysosomes for degradation [46]. KIM-1 also mediates the phagocytosis of necrotic cells and oxidized lipoproteins, and may therefore promote the repair of injured renal tubular epithelium [47]. Furthermore, KIM-1 may play a role in modulating the immune response during IRI via the leukocyte mono-immunoglobulin-like receptor 5 (LMIR5)/CD300 [46]. KIM-1 has been evaluated in multiple models of human AKI and demonstrated variable diagnostic performance, which may be related in part to the delayed peak in urinary KIM-1 compared to other biomarkers [48].

\section{Proteomics}

Proteomic techniques typically involve an initial protein separation step to reduce sample complexity. This is necessary to decrease the "noise" generated by high-abundance proteins, so peptide/protein identification with tandem mass spectrometry (MS-MS) can be performed. Examples of separation techniques include surface-enhanced laser desorption ionization time of flight mass spectrometry (SELDI TOF-MS) chips which differentially bind proteins based on their biochemical characteristics (e.g. hydrophobic, cationic), capillary electrophoresis with differential sample elution times based on size and charge and two-dimensional (2D) gel electrophoresis where samples are also differentially resolved by size and charge. In-depth, semi-quantitative discovery proteomics are usually performed in small sample numbers due to the complexity and cost of analysis. Therefore, targets identified with these techniques are strictly hypothesis-generating and require additional quantitative validation in larger cohorts.

\section{MS-based proteomics}

SELDI TOF-MS was used to identify hepcidin-25 in a prospective, nested case-control population $(n=44)$ [49]. SELDI TOF-MS demonstrated a $2.78-\mathrm{kDa}$ protein peak that was differentially up-regulated at post-operative day 1 in non-AKI versus AKI patients. This protein was isolated with ion exchange chromatography, purified by reverse phase-high-performance liquid chromatography (RPHPLC) and identified with MS-MS [49]. These results were subsequently validated in an urinary hepcidin- 25 enzymelinked immunosorbent assay (ELISA) in a larger prospective cohort $(n=345)$ [50]. This result demonstrated that the urinary hepcidin-25:creatinine ratio is strongly and independently associated with avoidance of AKI [odds ratio (OR) 0.26, $95 \%$ confidence interval (CI) $0.12-0.58, p<0.0001)]$ with an AUC of 0.80 (95\% CI 0.70-0.89) [50]. Furthermore, hepcidin-25 has a strong negative predictive value of 0.96 for ruling out AKI and is associated with preservation of renal function [50]. These findings have since been independently confirmed in two prospective adult cardiac surgery cohorts [51, 52]. Hepcidin-25 is an antimicrobial peptide and regulator of iron homeostasis which may be renoprotective in IRI via iron sequestration. It is uniquely associated with avoidance of AKI and may complement biomarkers that detect renal injury. 
SELDI TOF-MS detected novel urine protein peaks at 6.4, 28.5, 43 and $66 \mathrm{kDa}$ associated with AKI in a prospective cohort of pediatric cardiac surgery patients $(n=60)$ [53] that were identified as aprotinin, $\alpha 1$-microglobulin, $\alpha 1$-acid glycoprotein and albumin, respectively $[54,55]$. Urinary aprotinin quantity was evaluated in a pediatric cardiac surgery cohort $(n=106)$ utilizing SELDI TOF-MS peak intensity (AUC 0.92), and aprotinin activity was assessed with a functional activity assay (AUC 0.98) [54]. Urinary aprotinin activity significantly correlated with aprotinin dose, suggesting that the amount of anti-thrombolytic (aprotinin) administered on cardiopulmonary bypass (CPB) caused the observed increase in amount and activity [54]. This correlation is supported by the multivariate model which demonstrated that prolonged CPB time and aprotinin use were the only significant predictors of AKI, suggesting that aprotinin may have limited utility as an AKI biomarker [54]. Urinary $\alpha 1$ microglobulin, $\alpha 1$-acid glycoprotein and albumin were also evaluated in a pediatric cardiac surgery population (test set $n=$ 30 , validation set $n=365$ ) and demonstrated an AUC of 0.84 , 0.87 and 0.76 , respectively, at $6 \mathrm{~h}$ after cardiac surgery [55]. Importantly, these three biomarkers are measurable by nephelometry, which is a high-throughput technique and easily accessible to clinical laboratories.

A variant of human $\beta$ defensin-1 and an unidentified protein peak $(4,631 \mathrm{Da})$ were detected with SELDI TOFMS in a nested case-control study of pediatric cardiac catheterization patients $(n=17)$ [56]. In the pre-procedural urine samples, human $\beta$ defensin-1 was elevated in nonAKI patients (AUC 0.89-0.99), and the 4,631-Da peak (AUC 0.84) was elevated in AKI patients [56]. Human $\beta$ defensin- 1 is an antimicrobial peptide, similar to NGAL and hepcidin-25, and it has been postulated that it may have a renoprotective effect. The 4,631-Da peak has yet to be identified, and this illustrates a critical limitation of SELDI TOF-MS. SELDI TOF-MS is a high-throughput platform for detecting differentially expressed protein peaks, but the translation of these "diagnostic" peaks into clinical laboratory testing is not practical due to the sample processing and infrastructure required. Therefore, the utility of SELDI TOF-MS hinges on the ability to isolate and identify the specific protein so it can be translated into an assay appropriate for clinical use. The proteins analyzed are restricted to those with the specific biochemical properties that bind the SELDI chip and therefore show a limited portion of the proteome. Furthermore, SELDI TOF-MS is optimized to the low molecular weight range and has poor resolution for high molecular weight proteins. Finally, SELDI TOFMS is semi-quantitative and requires quantitative validation.

Capillary electrophoresis mass spectrometry has been used to identify 20 urine peptides that were the degradation products of six proteins from a critical care model of AKI $(n=20)$. Adult AKI patients were found to have increased albumin, $\alpha 1$ - antitrypsin and $\beta 2$-microglobulin peptides, as well as decreased fibrinogen- $\alpha$, collagen $1 \alpha$ (I) and collagen $1 \alpha$ (III) peptides [57]. The diagnostic performance of the combined peptide panel demonstrated an AUC of 0.91, and these results were then tested in an independent ICU patient population $(n=$ 20, AUC 0.84) and hematopoietic stem cell transplant cohort ( $n=31$, AUC 0.90) [57]. The $\beta 2$-microglobulin and albumin data are consistent with data reported previously [49, 55]. MSbased techniques, such as capillary electrophoresis-MS, are invaluable for unbiased biomarker discovery. However, the translation of MS-based assays to the bedside is impaired by expensive infrastructure, complex sample processing and the need for technical expertise. Unfortunately, attaining antibodies with epitopes specific to biomarker peptides that do not exhibit cross-reactivity with their parent molecules may prove very challenging. This may further limit the applicability of peptide-based diagnostics to wider dissemination since most quantitative, high-throughput platforms are antibody-based.

Differential protein profiling identified chitinase 3-like protein 1 in a rat model of sepsis [58]. Rat septic AKI and non-AKI urine samples were compared by labeling with light versus heavy isotopes using propionylation [58]. The light and heavy isotope-labeled samples were combined and subjected to MSMS for identification of differentially regulated proteins. This affinity tag adds a predictable mass/charge separation and therefore allows for the determination of relative abundance at the same time as protein identification. Other examples of differential labeling include isotope coded affinity tags, $O$ methylisourea and isobaric tag for relative and absolute quantitation (iTRAQ) [59]. Eight protein candidates have been validated with western blot: NGAL, thioredoxin, gelsolin, chitinase 3-like protein 3, sepiapterin reductase, osteopontin, cathepsin L1 and uteroglobin [58]. In a small cohort of septic patients $(n=12)$ chitinase 3 -like protein 1 was found to be elevated in septic AKI in a pattern similar to NGAL [58]. Differential protein profiling is a powerful method for identifying differentially expressed proteins; however, it can be limited by the extent to which the label is incorporated in a sample. For example, ICAT labels are incorporated at cysteines, $O$-methylisourea is incorporated at trypsin digestion sites, and iTRAQ labels are incorporated at N-terminal or lysine side chains. Therefore, relative abundances will not be determined for peptides that do not have these specific labeling sites.

\section{Gel-based proteomics}

Two-dimensional fluorescence difference gel electrophoresis (2D DIGE) has also been used to identify novel biomarkers of AKI. In a small nested case-control study of adult cardiac surgery patients $(n=12), 2 \mathrm{D}$ DIGE identified four differentially regulated proteins in AKI versus non-AKI patients, including zinc $\alpha 2$-glycoprotein [60]. Zinc $\alpha 2$ glycoprotein was then quantified with western blot and 
ELISA to demonstrate an AUC of 0.68 [60]. Urinary exosomal fetuin-A was also identified with 2D DIGE in different rat models of AKI (IRI, cisplatin and prerenal azotemia) [61]. Urinary exosomal fetuin-A is significantly increased in $\mathrm{AKI}$, and these findings were evaluated by western blot in a very small group $(n=6)$ of ICU patients [61]. Although 2D DIGE can be a powerful method for identifying differentially expressed proteins, gel-based proteomics is significantly limited in its ability to identify low-abundance proteins. Furthermore, small relative changes in protein abundance that may be physiologically relevant may not be detected with gelbased techniques as they lack the resolution of in-solution approaches (e.g. capillary electrophoresis, RP-HPLC).

\section{Metabolomics}

Mass spectrometry-based metabolomics was used in a prospective cohort of pediatric cardiac surgery patients $(n=40)$ to identify homovanillic acid sulphate (HVA-SO ${ }_{4}$ ), a dopamine metabolite, as being associated with AKI [62]. The diagnostic performance of HVA-SO $\mathrm{S}_{4}$ demonstrated an AUC of 0.78 at $4 \mathrm{~h}$ post-cardiac surgery for identifying AKI, defined as a serum creatinine rise of $\geq 50 \%$ from baseline. The group with AKI tended to have significantly longer CPB times and lengths of hospital stay, suggesting a sicker cohort. One of the limitations of this study was that vasopressor support was not listed; therefore, it is unknown whether the increase in dopamine metabolites identified in the AKI group was confounded by exogenous dopamine administration. Metabolomics may be limited in translating to clinical practice because of the need for expensive infrastructure, operator expertise and complex sample handling (e.g. nuclear magnetic resonance, MS-MS).

\section{Challenges and limitations}

In addition to technology-specific methodological limitations, there are currently no standardized criteria for urine and serum (or plasma) sample processing, which can further confound biological variability with extra technical variability. One of the advantages in studying children is that biological variability may be decreased due to a lower co-morbid burden; however, this may be off-set by inherent age-dependent developmental variability. Therefore, it is imperative that novel biomarkers undergo independent validation in large, prospective cohorts that are sufficiently powered to evaluate diagnostic performance. Furthermore, it is important that biomarkers be tested in different AKI clinical settings to ensure generalizability. Ideally, biomarker candidates should be sensitive, specific, accurate within a broad dynamic range and easily quantifiable on accessible, high-throughput platforms.

\section{Future directions in proteomics}

Activity-based protein profiling (ABPP) is a new technique that is based on the use of probes that selectively and irreversibly bind to the active conformational site of an enzyme family (e.g. serine hydrolase, cysteine protease). ABPP can demonstrate differential enzyme activity, and the probes can be used for affinity purification and enzyme identification on MS-MS [63, 64]. This unbiased analysis provides important functional insight, since enzyme activity can be independent from enzyme quantity based on the current conformational state. Critically, if differentiallyactivated urinary enzymes can be identified in AKI it may be possible to develop a rapid, colorimetric or fluorometric point-of-care screening assay based on immobilizing the substrate to a test strip to create a "urine dipstick" for AKI.

\section{Conclusion}

The "-omics" technologies offer an unbiased approach to identifying novel biomarkers of AKI. These techniques can be integrated with, and are complementary to, traditional hypothesis-driven approaches and provide additional armamentarium for discovery-based biomarker studies. These techniques can provide novel insights into the underlying pathophysiology of AKI and may also identify novel therapeutic targets. There are $>1,500$ proteins in normal urine alone. While nephrologists have made excellent clinical diagnostic and prognostic use of urinary protein and albuminuria, it is possible to delve much deeper into the urinary proteome to maximize its diagnostic and prognostic potential. Ultimately, the early diagnosis of AKI will provide a means to stratify patients for early interventional AKI trials in the hope that the morbidity and mortality associated with AKI may be reduced by the discovery and implementation of effective therapies.

Acknowledgments Dr. Ho is funded by the Canadian Institutes of Health Research, The Kidney Foundation of Canada and the KRESCENT New Investigator Program.

Financial disclosure None.

\section{References}

1. Parikh CR, Devarajan P, Zappitelli M, Sint K, Thiessen-Philbrook H, Li S, Kim RW, Koyner JL, Coca SG, Edelstein CL, Shlipak MG, Garg AX, Krawczeski CD (2011) Postoperative biomarkers predict acute kidney injury and poor outcomes after pediatric cardiac surgery. J Am Soc Nephrol 22:1737-1747

2. Parikh CR, Coca SG, Thiessen-Philbrook H, Shlipak MG, Koyner JL, Wang Z, Edelstein CL, Devarajan P, Patel UD, Zappitelli M, Krawczeski CD, Passik CS, Swaminathan M, Garg AX (2011) Postoperative biomarkers predict acute kidney injury and poor 
outcomes after adult cardiac surgery. J Am Soc Nephrol 22:17481757

3. Kidney Disease: Improving Global Outcomes (KDIGO) Acute Kidney Injury Work Group (2012) KDGIO Clinical Practice Guideline for Acute Kidney Injury. Kidney Int Suppl 2:1-138

4. Schneider J, Khemani R, Grushkin C, Bart R (2010) Serum creatinine as stratified in the RIFLE score for acute kidney injury is associated with mortality and length of stay for children in the pediatric intensive care unit. Crit Care Med 38:933-939

5. Plötz FB, Bouma AB, van Wijk JA, Kneyber MC, Bökenkamp A (2008) Pediatric acute kidney injury in the ICU: an independent evaluation of pRIFLE criteria. Intensive Care Med 34:1713-1717

6. Akcan-Arikan A, Zappitelli M, Loftis LL, Washburn KK, Jefferson LS, Goldstein SL (2007) Modified RIFLE criteria in critically ill children with acute kidney injury. Kidney Int 71:1028-1035

7. Symons JM, Chua AN, Somers MJ, Baum MA, Bunchman TE, Benfield MR, Brophy PD, Blowey D, Fortenberry JD, Chand D, Flores FX, Hackbarth R, Alexander SR, Mahan J, McBryde KD, Goldstein SL (2007) Demographic characteristics of pediatric continuous renal replacement therapy: a report of the prospective pediatric continuous renal replacement therapy registry. Clin J Am Soc Nephrol 2:732-738

8. Prince JF, Mott AR, Dickerson HA, Jeffries JL, Nelson DP, Chang AC, Smith EO, Towbin JA, Dreyer WJ, Denfield SW, Goldstein SL (2008) Worsening renal function in children hospitalized with decompensated heart failure: evidence for a pediatric cardiorenal syndrome? Pediatr Crit Care 9:279-284

9. Askenazi DJ, Feig DI, Graham NM, Hui-Stickle S, Goldstein SL (2006) 3-5 year longitudinal follow-up of pediatric patients after acute renal failure. Kidney Int 69:184-189

10. Goldstein SL, Devarajan P (2011) Acute kidney injury in childhood: should we be worried about progression to CKD? Pediatr Nephrol 26:509-522

11. Mammen C, Al Abbas A, Skippen P, Nadel H, Levine D, Collet JP, Matsell DG (2012) Long-term risk of CKD in children surviving episodes of acute kidney injury in the intensive care unit: a prospective cohort study. Am J Kidney Dis 59:523-530

12. Wald R, Quinn RR, Luo J, Li P, Scales DC, Mamdani MM, Ray JG (2009) Chronic dialysis and death among survivors of acute kidney injury requiring dialysis. JAMA 302:1179-1185

13. Coca SG, Singanamala S, Parikh CR (2012) Chronic kidney disease after acute kidney injury: a systematic review and metaanalysis. Kidney Int 81:442-448

14. Jones J, Holmen J, De Graauw J, Jovanovich A, Thornton S, Chonchol M (2012) Association of complete recovery from acute kidney injury with incident CKD stage 3 and all-cause mortality. Am J Kidney Dis 60:402-408

15. Greenbaum LA, Warady BA, Furth SL (2009) Current advances in chronic kidney disease in children: growth, cardiovascular, and neurocognitive risk factors. Semin Nephrol 29:425-434

16. Gerson AC, Wentz A, Abraham AG, Mendley SR, Hooper SR, Butler RW, Gispon DS, Lande MB, Shinnar S, Moxey-Mims MM, Warady BA, Furth SL (2010) Health-related quality of life of children with mild to moderate chronic kidney disease. Pediatrics 125:e349-e357

17. Bonventre JV, Weinberg JM (2003) Recent advances in the pathophysiology of ischemic acute renal failure. J Am Soc Nephrol 14:2199-2210

18. Devarajan P, Mishra J, Supavekin S, Patterson LT, Potter S (2003) Gene expression in early ischemic renal injury: clues towards pathogenesis, biomarker discovery, and novel therapeutics. Mol Genet Metab 80:365-376

19. Lameire N, Van Biesen W, Vanholder R (2005) Acute renal failure. Lancet 365:417-430

20. Bellomo R, Kellum JA, Ronco C (2004) Defining acute renal failure: pathophysiological principles. Intensive Care Med 30:33-37
21. Sutton TA, Fisher CJ, Molitoris BA (2002) Microvascular endothelial injury and dysfunction during ischemic acute renal failure. Kidney Int 62:1539-1549

22. Filler GM (2011) The challenges of assessing acute kidney injury in infants. Kidney Int 80:567-568

23. Shlipak MG, Sarnak MJ, Katz R, Fried LF, Selinger SL, Newman AB, Siscovick DS, Stehman-Breen C (2005) Cystatin C and the risk of death and cardiovascular events among elderly persons. New Eng J Med 352:2049-2060

24. Krawczeski CD, Goldstein SL, Woo JG, Wang Y, Piyaphanee N, Ma Q, Bennett M, Devarajan P (2011) Temporal relationship and predictive value of urinary acute kidney injury biomarkers after pediatric cardiopulmonary bypass. J Am Coll Cardiol 58:2301-2309

25. Krawczeski CD, Woo JG, Wang Y, Bennett MR, Ma Q, Devarajan P (2011) Neutrophil gelatinase-associated lipocalin concentrations predict development of acute kidney injury in neonates and children after cardiopulmonary bypass. J Pediatr 158:1009-1015

26. Mishra J, Dent C, Tarabishi R, Mitsnefes MM, Ma Q, Kelly C, Ruff SM, Zahedi K, Shao M, Bean J, Mori K, Barasch J, Devarajan P (2005) Neutrophil gelatinase-associated lipocalin (NGAL) as a biomarker for acute renal injury after cardiac surgery. Lancet 365:1231-1238

27. Bennett M, Dent CL, Ma Q, Dastrala S, Grenier F, Workman R, Syed H, Ali S, Barasch J, Devarajan P (2008) Urine NGAL predicts severity of acute kidney injury after cardiac surgery: a prospective study. Clin J Am Soc Nephrol 3:665-673

28. Dent CL, Ma Q, Dastrala S, Bennett M, Mitsnefes MM, Barasch J, Devarajan P (2007) Plasma neutrophil gelatinase-associated lipocalin predicts acute kidney injury, morbidity and mortality after pediatric cardiac surgery: a prospective uncontrolled cohort study. Crit Care 11:R127

29. Zappitelli M, Washburn KK, Arikan AA, Loftis L, Ma Q, Devarajan P, Parikh CR, Goldstein SL (2007) Urine neutrophil gelatinaseassociated lipocalin is an early marker of acute kidney injury in critically ill children: a prospective cohort study. Crit Care 11:R84

30. Wheeler DS, Devarajan P, Ma Q, Harmon K, Monaco M, Cvijanovich N, Wong HR (2008) Serum neutrophil gelatinase-associated lipocalin (NGAL) as a marker of acute kidney injury in critically ill children with septic shock. Crit Care Med 36:1297-1303

31. Du Y, Zappitelli M, Mian A, Bennett M, Ma Q, Devarajan P, Mehta R, Goldstein SL (2011) Urinary biomarkers to detect acute kidney injury in the pediatric emergency center. Pediatr Nephrol 26:267-274

32. Parikh CR, Mishra J, Thiessen-Philbrook H, Dursun B, Ma Q, Kelly C, Dent C, Devarajan P, Edelstein CL (2006) Urinary IL-18 is an early predictive biomarker of acute kidney injury after cardiac surgery. Kidney Int 70:199-203

33. Han WK, Waikar SS, Johnson A, Betensky RA, Dent CL, Devarajan P, Bonventre JV (2008) Urinary biomarkers in the early diagnosis of acute kidney injury. Kidney Int 73:863-869

34. Portilla D, Dent C, Sugaya T, Nagothu KK, Kundi I, Moore P, Noiri E, Devarajan P (2008) Liver fatty acid-binding protein as a biomarker of acute kidney injury after cardiac surgery. Kidney Int 73:465-472

35. Zappitelli M, Krawczeski CD, Devarajan P, Wang Z, Sint K, Thiessen-Philbrook H, Li S, Bennett MR, Ma Q, Shlipak MG, Garg AX, Parikh CR, TRIBE-AKI consortium (2011) Early postoperative serum cystatin $\mathrm{C}$ predicts severe acute kidney injury following pediatric cardiac surgery. Kidney Int 80:655-662

36. Krawczeski CD, Vandevoorde RG, Kathman T, Bennett MR, Woo JG, Wang Y, Griffiths RE, Devarajan P (2010) Serum cystatin C is an early predictive biomarker of acute kidney injury after pediatric cardiopulmonary bypass. Clin J Am Soc Nephrol 5:1552-1557

37. Hassinger AB, Backer CL, Lane JC, Haymond S, Wang D, Wald EL (2012) Predictive power of serum cystatin C to detect acute kidney injury and pediatric-modified RIFLE class in children undergoing cardiac surgery. Pediatr Crit Care Med 13:435-440 
38. Zappitelli M, Coca SG, Garg AX, Krawczeski CD, Thiessen Philbrook H, Sint K, Li S, Parikh CR, Devarajan P, TRIBE-AKI consortium (2012) The association of albumin/creatinine ratio with postoperative AKI in children undergoing cardiac surgery. Clin J Am Soc Nephrol 7:1761-1769

39. Shlipak MG, Coca SG, Wang Z, Devarajan P, Koyner JL, Patel UD, Thiessen-Philbrook H, Garg AX, Parikh CR; TRIBE-AKI consortium (2011) Presurgical serum cystatin $\mathrm{C}$ and risk of acute kidney injury after cardiac surgery. Am J Kidney Dis 58:366-373

40. Mishra J, Ma Q, Prada A, Mitsnefes M, Zahedi K, Yang J, Barasch J, Devarajan P (2003) Identification of neutrophil gelatinase-associated lipocalin as a novel early urinary biomarker for ischemic renal injury. J Am Soc Nephrol 14:25342543

41. Mori K, Lee HT, Rapoport D, Drexler IR, Foster K, Yang J, Schmidt-Ott KM, Chen X, Li JY, Weiss S, Mishra J, Cheema FH, Markowitz G, Suganami T, Sawai K, Mukoyama M, Kunis C, D'Agati V, Devarajan P, Barasch J (2005) Endocytic delivery of lipocalin-siderophore-iron complex rescues the kidney from ischemia-reperfusion injury. J Clin Invest 115:610-621

42. Mishra J, Mori K, Ma Q, Kelly C, Yang J, Mitsnefes M, Barasch J, Devarajan P (2004) Amelioration of ischemic acute renal injury by neutrophil gelatinase-associated lipocalin. J Am Soc Nephrol 15:3073-3082

43. Haase M, Bellomo R, Devarajan P, Schlattmann P, Haase-Fielitz A, NGAL Meta-analysis Investigator Group (2009) Accuracy of neutrophil gelatinase-associated lipocalin (NGAL) in diagnosis and prognosis in acute kidney injury: a systematic review and meta-analysis. Am J Kidney Dis 54:1012-1024

44. Ichimura T, Bonventre JV, Bailly V, Wei H, Hession CA, Cate RL, Sanicola M (1998) Kidney injury molecule-1 (KIM-1), a putative epithelial cell adhesion molecule containing a novel immunoglobulin domain, is up-regulated in renal cells after injury. J Biol Chem 273:4135-4142

45. Han WK, Bailly V, Abichandani R, Thadhani R, Bonventre JV (2002) Kidney injury molecule-1 (KIM-1): a novel biomarker for human renal proximal tubule injury. Kidney Int 62:237-244

46. Bonventre JV, Yang L (2010) Kidney injury molecule-1. Curr Opin Crit Care 16:556-561

47. Bonventre JV, Yang L (2011) Cellular pathophysiology of ischemic acute kidney injury. J Clin Invest 121:4210-4221

48. Han WK, Wagener G, Zhu Y, Wang S, Lee HT (2009) Urinary biomarkers in the early detection of acute kidney injury after cardiac surgery. Clin J Am Soc Nephrol 4:873-882

49. Ho J, Lucy M, Krokhin O, Hayglass K, Pascoe E, Darroch G, Rush D, Nickerson P, Rigatto C, Reslerova M (2009) Mass spectrometry-based proteomic analysis of urine in acute kidney injury following cardiopulmonary bypass: a nested case control study. Am J Kidney Dis 53:584-595

50. Ho J, Reslerova M, Gali B, Gao A, Bestland J, Rush DN, Nickerson PW, Rigatto C (2011) Urinary hepcidin-25 and risk of acute kidney injury following cardiopulmonary bypass. Clin J Am Soc Nephrol 6:2340-2346
51. Haase-Fielitz A, Mertens PR, Plass M, Kuppe H, Hetzer R, Westerman M, Ostland V, Prowle JR, Bellomo R, Haase M (2011) Urine hepcidin has additive value in ruling out cardiopulmonary bypass-associated acute kidney injury — an observational cohort study. Crit Care 15:R186

52. Prowle JR, Ostland V, Calzavacca P, Licari E, Ligabo EV, Echeverri JE, Bagshaw SM, Haase-Fielitz A, Haase M, Westerman M, Bellomo $\mathrm{R}$ (2012) Greater increase in urinary hepcidin predicts protection from acute kidney injury after cardiopulmonary bypass. Nephrol Dial Transplant 27:595-602

53. Nguyen MT, Ross GF, Dent CL, Devarajan P (2005) Early prediction of acute renal injury using urinary proteomics. Am J Nephrol 25:318-326

54. Nguyen MT, Dent CL, Ross GF, Harris N, Manning PB, Mitsnefes MM, Devarajan P (2008) Urinary aprotinin as a predictor of acute kidney injury after cardiac surgery in children receiving aprotinin therapy. Pediatr Nephrol 23:1317-1326

55. Devarajan P, Krawczeski CD, Nguyen MT, Kathman T, Wang Z, Parikh CR (2010) Proteomic identification of early biomarkers of acute kidney injury after cardiac surgery in children. Am J Kidney Dis $56: 632-642$

56. Bennett MR, Ravipati N, Ross G, Nguyen MT, Hirsch R, Beekman RH, Rovner L, Devarajan P (2008) Using proteomics to identify preprocedural risk factors for contrast induced nephropathy. Proteomics Clin Appl 2:1058-1064

57. Metzger J, Kirsch T, Schiffer E, Ulger P, Mentes E, Brand K, Weissinger EM, Haubitz H, Mischak H, Herget-Rosenthal S (2010) Urinary excretion of twenty peptides forms an early and accurate diagnostic pattern of acute kidney injury. Kidney Int 78:1252-1262

58. Maddens B, Ghesquière B, Vanholder R, Demon D, Vanmassenhove J, Gevaert K, Meyer E (2012) Chitinase-like proteins are candidate biomarkers for sepsis-induced acute kidney injury. Mol Cell Proteomics 11:M111.013094

59. Gygi SP, Rist B, Gerber SA, Turecek F, Gelb MH, Aebersold R (1999) Quantitative analysis of complex protein mixtures using isotope-coded affinity tags. Nat Biotechnol 17:994-999

60. Aregger F, Pilop C, Uehlinger DE, Brunisholtz R, Carrel TP, Frey FJ, Frey BM (2010) Urinary proteomics before and after extracorporeal circulation in patients with and without acute kidney injury. J Thorac Cardiovasc Surg 139:692-700

61. Zhou H, Pisitkun T, Aponte A, Yuen PS, Hoffert JD, Yasuda H, Hu X, Chawla L, Shen RF, Knepper MA, Star RA (2006) Exosomal fetuin-A identified by proteomics: a novel urinary biomarker for detecting acute kidney injury. Kidney Int 70:1847-1857

62. Beger RD, Holland RD, Sun J, Schnackenberg LK, Moore PC, Dent CL, Devarajan P, Portilla D (2008) Metabonomics of acute kidney injury in children after cardiac surgery. Pediatr Nephrol 23:977-984

63. Cravatt BF, Wright AT, Kozarich JW (2008) Activity-based protein profiling: from enzyme chemistry to proteomic chemistry. Annu Rev Biochem 77:383-414

64. Liu Y, Patricelli MP, Cravatt BF (1999) Activity-based protein profiling: the serine hydrolases. Proc Natl Acad Sci USA 96:14694-14699 